\title{
Apontamentos sobre as relações de gênero em rodas de capoeira em Amambai/MS
}

\author{
Tânia Zimmermann* \\ Márcia Maria de Medeiros** \\ Deborah Henning Barrizon***
}

Palavras-chave:

Capoeira

Relações de Gênero

História

Keywords:

Capoeira

Gender Relations

History

\begin{abstract}
Resumo: Esta pesquisa permitiu analisar algumas configurações de gênero em jogos de capoeira na cidade de Amambaí, Mato Grosso do Sul no tempo presente, utilizando a história oral como a principal metodologia com o objetivo de examinar a produção de relações sociais e de diferenciações entre mulheres e homens. Também discutimos, a partir das fontes bibliográficas, aspectos do processo de construção do gênero em rodas de capoeira no Brasil e, especialmente, o modo de entrada das mulheres e como resistiram para se posicionar no espaço destas práticas culturais em relação ao modelo hegemônico de masculinidade. Procuramos entender também aspectos históricos sobre a construção da diferenciação negativa de determinados povos a partir de algumas discussões sobre a História Africana e Afro-brasileira e a inserção da capoeira como possibilidade de reinvenção de práticas de identificações e de solidariedade entre mulheres e homens.
\end{abstract}

\begin{abstract}
This research allowed us to analyze some kind of settings in capoeira games in the city of Amambaí, Mato Grosso do Sul in the present tense, using oral history as the main methodology in order to examine the production of social relations and differences between women and men. We also discussed, from literature sources, aspects of gender construction process in capoeira in Brazil and especially the women's input mode and how resisted to position in space of these cultural practices in relation to the hegemonic model of masculinity. We also seek to understand historical aspects of the construction of the negative differentiation of certain people from some discussions on African History and Afro-Brazilian and the inclusion of capoeira as a possibility of reinvention practices identity and solidarity between women and men.
\end{abstract}

Recebido em 07 de outubro de 2016. Aprovado em 20 de dezembro de 2016.

\section{Introdução}

Ao analisarmos bibliografias referentes à história da capoeira, percebemos que existe uma riqueza de informações. Os mais variados pesquisadores $^{1}$, em suas produções, percebem a capoeira não somente como uma expressão corporal e musical brasileira mas também como a expressão das múltiplas identidades africanas na cultura brasileira, esta que, por meio de gestos únicos, transmite a quem participa a possibilidade de entender a história desta miríade de povos que constituíram elemento importante na formação do nosso país.
A capoeira constitui-se, ao longo dos séculos, em um processo que permitiu a construção de um referencial identitário para os negros da mesma forma que passou a participar expressivamente na construção da identidade nacional conforme explicitam Abreu, Oliveira e Leal (2009, p. 17): "A capoeira finalmente torna-se parte integrante da história do país, da sua face, da sua gênese, faceta antes percebida, mas nunca explicitada”.

A partir do momento em que as práticas culturais dos afro-brasileiros tiveram uma atenção especial na academia, passaram a pulular estudos sobre os vários significados dessas práticas.

\footnotetext{
* Professora do curso de História e dos programas de pós-graduação em Educação e Professora de História da Universidade Estadual de Mato Grosso do Sul (UEMS). E-mail: taniazimmermann@gmail.com

** Professora dos Cursos de Letras e Enfermagem e do Programa de Pós-Graduação em Letras (PROFLETRAS) e do Mestrado em Ensino e Saúde da Universidade Estadual de Mato Grosso do Sul (UEMS).E-mail: maeve35@hotmail.com

*** Graduanda em História pela Universidade Estadual de Mato Grosso do Sul (UEMS) e bolsista CNPq/PIBIC. E-mail: deborahenning18@hotmail.com
} 
No caso desta pesquisa, interessa-nos aqui trilhar pelos estudos de gênero para, por intermédio deste olhar, entender o papel das mulheres nos jogos de capoeira em Amambaí/ MS.

Ao referimo-nos às relações de gênero, partimos, inicialmente, das diferenças culturais entre mulheres e homens, pois estas direcionam o foco para o que caracteriza e justifica a desigualdade, e, a partir disso, geralmente se secundariza o entendimento das relações sociais de gênero.

Portanto, seguimos o trabalho de Joan Scott, no qual o gênero se refere a uma construção histórica das relações de poder entre homens e mulheres, devendo contemplar definições plurais de gênero, assim como de masculinidade e feminilidade (SCOTT, 1990). Os estudos de gênero e os conceitos correlatos variaram ao longo da história. Por isso, Scott acentua que gênero refere-se às relações sociais nas quais indivíduos e grupos atuam.

Procuramos demonstrar que a densidade da análise histórica a partir do gênero enquanto uma categoria apresenta uma diversidade de esferas nas quais as relações não se dão de maneira isolada, $e$ sim de forma integrada com outras relações sociais, sejam elas de classe, de religião, de geração, raciais ou étnicas (SCOTT, 1990).

No século XIX, os jogos de capoeira enquanto práticas culturais foram considerados ilegais. No entanto, 100 anos depois (século $\mathrm{XX}$ ) afloraram como atividade significativa e representativa da cultura e identidade brasileira. As lutas por parte da população negra do Brasil, organizada em movimentos sociais e buscando através dessa luta um conjunto de ações afirmativas se materializou na obrigatoriedade do ensino de história da África e cultura afro-brasileira e africana na Educação Básica e nas universidades. Nesse contexto, a capoeira enquanto guardiã de saberes e de proteção material, é um dos elementos dessa cultura plural.

Essa lógica de valorização e reconhecimento da cultura africana atingiu também a cidade de Amambai, município que se situa ao sul do estado do Mato Grosso do Sul e soma atualmente $37 \mathrm{mil}$ habitantes, de acordo com o IBGE. Na cidade, a capoeira teve seus começos com o Grupo Ginga Capoeira, o qual iniciou as atividades a partir de fevereiro de 2014, sob a condução do mestre Rodrigo Xavier. Xavier desenvolveu trabalhos em escolas, academias - como a Dragões de Fogo -, instituições educacionais - como Guarda Mirim, a Associação de Pais e Amigos dos Excepcionais (APAE) e o Centro de Referência Especializado de Assistência Social (CREAS) e realizou projetos de capoeira com pessoas portadoras de necessidades especiais e continua atualmente com projetos de capoeira.

Interessa-nos perceber, através da história $\mathrm{oral}^{2}$, as intricadas relações de gênero que se estabelecem no interior dessas rodas de capoeira. Para isso, partimos do pressuposto de Foucault (1982), segundo o qual as relações de poder estão dispersas, ou seja, são relacionais e não estão concentradas em algum ponto fixo como no Estado e também não são relações estáveis. Considerando que estas relações estão imbricadas com as relações de gênero, perguntamos como estas práticas permitiam e como permitem o acesso às mulheres nas rodas de capoeira?

Então, fica evidente que as categorias gênero e masculinidade tornam-se relevantes para compreender essas relações de poder. Assim como outras práticas significativas, o jogo da capoeira também é condicionado por valores e regras de poder e de gênero que influenciam na sua materialização. Como construção social, a capoeira é, também, uma manifestação cultural que permanentemente se constrói.

Nos séculos XIX e XX, as atividades físicas, como lutas e esportes coletivos, eram consideradas um campo de atuação masculino; logo, imputavam barreiras culturais para a inserção das mulheres. Com isso, dava-se continuidade ao modelo de masculinidade hegemônica, ou seja, a masculinidade e a virilidade estavam associadas às lutas $\mathrm{e}$, consequentemente, também aos jogos de capoeira. Foram poucas as mulheres que ingressaram nestas práticas culturais relacionadas a tais atividades.

No tempo presente, percebe-se uma maior inserção de mulheres nessas atividades, incluindo aqui o local da pesquisa; mas ainda existem 
diferenças em relação aos homens, as quais se convertem em desigualdades como a possibilidade de que mulheres se tornem mestres na capoeira.

Embora as lutas feministas venham a ser as grandes tributárias das novas inserções conquistadas pelas mulheres no espaço público, ainda há vários impeditivos para a presença delas na capoeira: a dupla jornada de trabalho e os atributos sociais associados à família, não restando tempo para treinos, viagens e participação em eventos (ABREU; OLIVEIRA; LEAL, 2009).

Também se observa que, mesmo com a ascensão de mulheres à condição de mestras no jogo, não há um reconhecimento igualitário em relação aos homens. Além disso, em Amambai, conforme veremos nesta pesquisa, as mulheres sequer tornam-se mestras nesta prática.

\section{Apontamentos históricos da capoeira no Brasil}

Mandinga de escravo em ânsia de liberdade, seu princípio não tem método e seu fim é inconcebível ao mais sábio capoeirista.

Mestre Pastinha

Quando discutimos sobre as relações de gênero, principalmente no Brasil, percebemos que a prática da capoeira é claramente influenciada pelo tempo histórico em que se situam esta prática e pelos interesses que norteiam os sujeitos que, por meio daqueles, atuam e disputam poder na sociedade. Nos primórdios da constituição da capoeira esta se traduzia em irreverência, malícia, improvisação e surpresa. Atualmente, esta prática tem se apresentado como um espetáculo, podendo apresentar competições e performances.

Para compreendermos as relações de gênero nas práticas da capoeira ocorridas na cidade de Amambai no Mato Grosso do Sul, partimos de breves olhares à história dessa atividade cultural em seus primórdios e alguns conflitos étnicos envolvendo afro-brasileiros. Sobretudo, devemos refletir sobre alguns olhares relativos à construção dos afrodescendentes. Segundo Santos, Denis Diderot considera homem aquele que: "Sente, reflete, pensa, que passeia livremente pelo planeta [...] homem parece estar à cabeça e dominar os outros animais, que o ser - humano vive em sociedade e inventou as artes, as ciências e as leis e, além disso, teria uma bondade que lhe seria própria" (DIDEROT, 2002 apud SANTOS, 2002, p. 25).

Com essa afirmação de Diderot, citada por Santos na obra A invenção do ser Negro (2002), percebemos que era necessário uma tipologia do ser humano, ou seja, caracterizá-lo e defini-lo através de uma justificação científica para a produção de uma diferenciação negativa. Tanto Diderot, como outros intelectuais iluministas, entre eles Georges-Louis Leclerc, conde de Buffon (1707-1788), FrançoisMarie Arouet e Voltaire (1694-1778), declaravam que os humanos apresentam variações de cor, grandeza e forma. Assim, não seríamos compostos por várias espécies, mas sim por características diferentes (1778-1779, tomo 17, p. 840).

Dessa forma, Diderot, Voltaire, Buffon e outros filósofos iluministas do século XVIII passaram a investigar variações do homem, baseando-se em seus aspectos anatômicos e na cor da pele. Dessas investigações, surgiram os verbetes "negro", "mulato", "hotentote", "chinês" e tantos outros que se referem à diversidade humana (SANTOS, 2002, p. 32). De acordo com a autora, no verbete "negro" existe uma especificação na qual Diderot afirma que: "Não somente sua cor os distingue, mas eles diferem dos outros homens, pelos traços de seu rosto, narizes largos e chatos, lábios grossos, lã no lugar de cabelos, que parecem constituir uma nova espécie de homem" (DIDEROT, 2002 apud SANTOS, 2002, p. 32).

Muitos antes que o termo "raça" fosse construído para diferenciar um grupo de outro, a cor negra era vista como negativa. A perfeição que agora estaria relacionada à evolução, pressupunha a existência de povos inferiores ou "menos perfeitos" aos demais. Esses povos, considerados "menos evoluídos", ainda estariam no seu estado selvagem e/ou animal. Este é o ponto no qual os iluministas se apoiavam para a justificativa do negro inferior ao branco na sociedade e, conforme nos alude Santos: "Neste momento, a idéia [sic] de raça passa a funcionar como catalisador e solução para todos os problemas" (SANTOS, 2002, p. 48). 
Para Santos (2002), as características do ser humano construídas pelo discurso iluminista dividiram a humanidade de uma forma irreversível, separando pelo imaginário "grau de importância", determinando por sua "natureza" e sobrepondo uns a outros. Dentro desse pressuposto, através dos estudos de Charles Darwin, a questão da "raça" para alguns darwinistas passou a ser usada para a intolerância.

Muitos darwinistas acreditavam na chamada "raça pura", mais forte e sábia, que passaria a controlar e eliminar as "raças menos puras". O fato de o negro ter sido caracterizado como tipo inferior, ora biologicamente, ora pelo desenvolvimento de suas sociedades, introduz a existência de uma "raça superior", trazendo-a para o centro da história.

No entanto, é possível rastrear esse sentimento de intolerância em relação ao negro desde o século XVI, conforme aufere a citação de Santos, através da qual Jean Léon L'Africain, um muçulmano, transmitia esta imagem sobre o negro: "São brutos sem razão, sem inteligência e sem experiência. Eles não têm absolutamente nenhuma noção do que quer que seja. Eles assim vivem como as bestas, sem regras e sem lei" (COHEN ano??, apud SANTOS, 2002, p. 49).

Segundo Santos (2002), a representação que se fazia de África, era a de uma terra inóspita e terrível, de homens excluídos até mesmo por Deus e dados a vícios como a bebida e o sexo. Essa terra era constituída de homens que apenas sabiam beber e fornicar. Terra de seres considerados "anormais" que precisavam ser estudados e entendidos pela Europa "civilizada" e branca, a qual era tomada como contraponto de uma cultura que não possuía altos feitos militares e científicos. Ao definir a anormalidade, intencionava-se definir e classificar o outro a partir da norma, pois conforme Canguilhem (2006, p. 109): "Normalizar é impor uma exigência a uma existência”, estabelecendo o que é normal e direito sugerindo o que precisa ser consertado, normalizado.

Percebemos que os traços físicos e a cor da pele estabeleciam uma hierarquia social que paulatinamente aumentavam as desigualdades, preconizando um jogo de oposição entre luz e sombra na qual o "branco" era considerado como um elemento simbólico da luz divina, enquanto o "negro" era visto como um elemento que preconizava as trevas, e, portanto, a ação demoníaca (SANTOS, 2002).

Voltando nossos olhares ao Brasil do século XVI, visando a compreender como se deu o processo de legitimação da capoeira enquanto "ícone contemporâneo representativo da identidade cultural brasileira" (ABREU; OLIVEIRA; LEAL, 2009, p. 43), Munanga e Gomes (2004) observam que os indígenas (assim como os negros) eram considerados seres de condição inferior aos europeus.

Assim, gradativamente, começaram as "missões civilizadoras" com o intuito de transformálos em índios de "alma branca". No discurso imposto pelos portugueses, estava a dominação dos indígenas com o propósito de escravidão. $\mathrm{Na}$ concepção de Santos (2002, p. 15), "todas as sociedades conheceram a escravidão como forma de exploração".

Com o tráfico negreiro, milhões de africanos foram escravizados para fornecer a força de trabalho necessária ao desenvolvimento português na colônia. De acordo com Munanga e Gomes (2004, p. 16), em muitos livros de história, encontramos a seguinte "justificativa" para o tráfico negreiro:

O índio, acostumado com a liberdade, recusou-se ao trabalho escravo, o que obrigou o colonizador português a buscar essa mão-de-obra [sic] escrava no continente africano onde os negros, acostumados com a escravidão já existente em sua terra, não se importavam com sua sorte.

Com a integração forçada dos traficados em navios negreiros, uma nova rede de amizades era formada entre os negros, que se identificavam como "malungos" ou companheiros de embarcação. Segundo Mattos (2007), quando chegaram ao Brasil, muitos desses "malungos" mantinham contato entre o grupo.

Em uma situação precária de sobrevivência, alguns conseguiram constituir famílias. Mas, obviamente, existiam dificuldades para essa 
construção familiar, conforme observa Mattos (2007, p. 175):

[...] Causadas, em certa medida, pela entrada de país de um maior número de africanos do sexo masculino e adultos na faixa dos 20-29 anos, pois se visava abastecer, em especial, as grandes propriedades com mão-de-obra [sic] produtiva. Esse fato acarretava o envelhecimento mais rápido $\mathrm{da}$ população escrava africana e menos tempo possível para encontrar um companheiro [...].

Mattos (2007) observa que, nas folgas do trabalhoárduo, geralmenteaos domingos, dias santos e festas religiosas, escravos e libertos se dirigiam até as praças, centros de comércio, ruas e espaços públicos para se divertirem e compartilharem seus costumes e manifestações culturais de dança, música e religiosidade. Esses encontros eram incentivados pelos seus proprietários na tentativa de evitar descontentamentos e rebeliões. Uma prática comum nesse ambiente era a capoeira.

Para proteger roubos de suas mercadorias que carregavam em cestos chamados de capoeiras, os negros de ganho movimentavam o corpo de maneira que pareciam fazer uma coreografia. Com isso, a capoeira se tornaria conhecida como uma dança ou brincadeira feita por escravos e libertos nas horas vagas.

O termo capoeira, originário do tupi guarani ("caapo", buraco de palha ou cesto de palha) e com o acréscimo europeu do termo "eiro" (de quem o carrega) aparece em dicionários do século XVIII e XIX com o significado de um tipo de um cesto de palha.

De acordo com Almir das Areias (1983), citado na obra "O negro no Brasil de hoje", de Munanga e Gomes (2004), a capoeira passou por quatro fases importantes:

1. A do início da escravidão, quando o escravizado, usando apenas o instinto de sobrevivência, tentava usar seu corpo para livrar-se do sofrimento e fugir.

2. A da áurea dos quilombos, na qual a capoeira já era uma das armas necessárias aos quilombolas para a defesa.
3. A da proibição oficial da capoeira após a Abolição.

4. A fase da sua liberação, no ano de 1932.

Segundo Abreu, Oliveira e Leal (2009), com a abolição da escravatura em 1888, descendentes de escravos africanos passaram a ocupar as ruas do Rio de Janeiro. Eram caracterizados como vagabundos, prostitutas e causadores da desordem pública. Assim, os capoeiras mantinham referências identitárias através da capoeira, e, dessa forma, o jogo também era alvo de preconceitos. Sobre isso Bretas aufere: "A imagem dos capoeiras é a reprodução das muitas faces da pobreza. Desfilavam cegos, pernetas, escrofulosos, todos reunidos sob o manto igualitário e discriminador de capoeiras" (BRETAS, 1999, p. 31).

No período republicano, houve a criminalização da capoeira no Brasil. Apesar dessa afirmação parecer atípica na atualidade, o fato se deu em todo o território brasileiro. A chamada "caça as bruxas" foi mais intensa no Distrito Federal (na época, localizado no Rio de Janeiro) e no estado do Rio de Janeiro. Para a polícia e parte da população do período, a prática da capoeira era realizada por vagabundos, vadios, bêbados, que infestam as ruas da capital (Rio de Janeiro), e provocam desordens a fim de insultar pessoas "sérias" (ABREU; OLIVEIRA; LEAL, 2009).

Nos começos da capoeira (ou capoeiragem, como também é conhecida), os praticantes eram homens negros, escravos e mestiços, mas havia mulheres que também compartilhavam o mesmo jogo e trocavam experiências. A capoeira caracterizava-se pela utilização do corpo como instrumento de luta, defesa e exibição: "Os escravizados não possuíam armas suficientes para se defender e descobriram formas de enfrentar as armas inimigas e o jugo da escravidão. A capoeira é uma delas" (MUNANGA; GOMES, 2004, p. 154):

Com os instrumentos berimbau, atabaque, pandeiro e agogô, com a ginga do corpo e a simulação de um combate ao som das ladainhas e cantigas, negros, mestiços e libertos se expressavam. A capoeira esteve relacionada a processos de resistência cultural dos africanos e seus descendentes em nosso país. 


\section{Mulheres na capoeira e capoeiristas amambaienses}

É inegável que o feminismo veio abalar a idéia [sic] de
uma masculinidade admitida como natural e, assim,
abriu caminho para o seu questionamento histórico.

Oliveira (1998, p. 108).

Segundo Abreu, Oliveira e Leal (2009), a prática da capoeira, em meados do século XX, nas ruas de Salvador inspirou crônicas urbanas. Percebemos que era uma prática associada ao homem e à masculinidade hegemônica por conter elementos de agressão física. Exemplos como a de Salomé, uma personagem da memória baiana, valente e decidida que frequentava as rodas de capoeira nas décadas de 1920 e 1930, são poucos, mas denotava a participação feminina.

Essas mulheres capoeiristas disputavam o jogo com os homens, usando pontapés e golpes e mostravam ser peritas nesse assunto. A rua era um lugar considerado perigoso e masculino sendo chamado de "poder do macho". Mulheres como Salomé, pobre e valente, que saíram de seu ambiente familiar doméstico, representaram um papel fundamental para práticas inventivas de liberdade para algumas mulheres.

Os jornais da época noticiaram mulheres capoeiristas como "desordeiras", por resistirem à prisão e lutarem contra homens. Algumas usavam navalhas em lutas corporais com muitos homens atuando também em grupos. Tal prática era considerada como "vagabundagem" ou "maus costumes". A mulher ideal ${ }^{3}$ desde a infância devia obediência ao pai, assim como aprender as prendas, os costumes de ser uma boa mãe, uma boa esposa. Seus comportamentos deveriam ser controlados, deveria ser santa, com uma fé inabalável, de acordo com as leis cristãs. As mulheres que praticavam capoeira quebravam esse paradoxo, deixando seus corpos com uma forte expressão libertária indo diretamente em confronto com a exclusividade da mulher como dona de casa (ABREU, OLIVEIRA; LEAL, 2009).
Sobre os comportamentos esperados e aqueles vividos pelas mulheres na capoeira, foi possível perceber dobras, fissuras, pontos de fuga. Nesse sentido, Judith Butler (2003, p. 20) reforça que:

Se alguém "ê" uma mulher, isso certamente não é tudo que esse alguém é, o termo não logra ser exaustivo, não por que os traços predefinidos de gênero da "pessoa" transcendam a parafernália específica de seu gênero, mas porque o gênero nem sempre se constituiu de maneira coerente ou consistente nos diferentes contextos históricos, e porque o gênero estabelece intersecções com modalidades raciais, classistas, étnicas, sexuais e regionais de identidades discursivamente constituídas.

Essa fuga do modelo de mulher ideal ia de encontro ao poder político que delimitava o lugar da mulher na sociedade. Com a colaboração do Jornal de Notícias, o poder político mobilizava o restante da população contra esse comportamento feminino inadequado, criando dogmas moralizadores e ridicularizando tais mulheres (ABREU; OLIVEIRA; LEAL, 2009).

Para Abreu (2009), os jornais dos começos do século XX, como o Jornal de Notícias de 1914 criticavam a polícia pela não intervenção frente aos capoeiristas. Seus nomes eram estampados em jornais como agressores de pessoas inocentes com a utilização de instrumentos de corte, como navalhas e afins. Ao enquadrar os capoeiras no Código Penal vigente do século XIX, tirar tal prática da criminalidade e colocá-la como um patrimônio cultural brasileiro não foi uma tarefa fácil.

As características da capoeira, bem como sua originalidade, foram de encontro aos costumes da elite do país. Além disso, não era considerada uma prática brasileira, pois advinha dos escravos africanos e seus valores estavam relacionados à marginalidade; por isso, as mulheres também estavam nesta margem (ABREU; OLIVEIRA; LEAL, 2009).

Percebemos, através das falas dos e das capoeiristas amambaienses, que as mulheres estiveram presentes nas rodas de capoeira, mas em menor número e em segundo plano, pois o destaque 
durante a luta era masculino segundo entrevistado [...] ela pode dar aula, mas ela não pode ser mestre". Assim, constata-se que as práticas de capoeira que emergiram nesta cidade ainda protagonizam a masculinidade hegemônica.

Nos séculos XIX e XX, as atividades físicas como lutas e esportes coletivos eram consideradas um campo de atuação masculino, por isso imputavam barreiras culturais para a inserção das mulheres. Assim, se dava continuidade ao modelo de masculinidade hegemônica, ou seja, uma masculinidade centrada na virilidade e associadas às lutas, e consequentemente os jogos de capoeira perpassavam esses comportamentos.

A conceituação da masculinidade na cultura ocidental é de que o masculino é ativo, sobretudo em relação às práticas sexuais. Então, é a atividade sexual que caracteriza a masculinidade? Sim. Mas ela pode ser construída de formas variadas como atesta a pesquisa de Peter Fry; afinal, em seus estudos sobre os comportamentos masculinos na Inglaterra e nos Estados Unidos, a sexualidade masculina deve ser exercida apenas com parceiras mulheres enquanto que no Brasil o homem é quem "come" mulheres e outros homens considerados feminilizados (apud GROSSI, 2004).

Para Connel (1995), a masculinidade hegemônica é um modo de viver e pensar que se difunde como elemento de direção controle ainda que não consciente. $\mathrm{O}$ conceito também está associado ao provimento e à produção, à sexualidade viril e sem controle, aos sentimentos de contenção e ao uso de força. Porém, observa que há masculinidades hegemônicas e periféricas ou variantes e ou concorrentes. Ademais, a autora observa que a categoria homem é atravessada pelas categorias de classe, raça, diferenças nacionais, regionais e geracionais (CONNEL, 2016, p. 99).

Mas a masculinidade dominante não se relaciona apenas ao ato sexual ativo, visto que há várias outras caracterizações como o domínio das emoções, a hiperatividade que se confunde com a agressividade (WELZER-LANG, 2001); daí a inserção prioritária dos homens nos jogos de capoeira por também ser considerada uma luta, incluindo aqui nosso local de pesquisa.
Em uma de nossas entrevistas, a fala de um capoeirista amambaiense em relação a participação feminina como mestres de capoeira, ele respondeu: "Nenhuma". E, em seguida, complementou "[...] porque eles dominam mais este jeito de jogar capoeira"4. Percebemos, nesta fala, que há uma elevação da masculinidade. Do mesmo modo que o entrevistado relata que não há mulher como mestre de capoeira, observa que existem mais homens mestres de capoeira, pois os homens levam mais "jeito" produzindo uma fala hierarquizada em relação ao gênero e com limitações para que mulheres se apropriem dessas práticas de forma igualitária.

Mulheres que praticavam capoeira quebravam o paradoxo da mulher dócil, submissa e resignada, cujas práticas traduziam-se como uma forte expressão libertária em confronto com a mulher dona de casa, cujo papel era claramente definido. Em todas as entrevistas, observou-se que mulheres se tornaram praticantes da capoeira na cidade de Amambai embora em menor número e, geralmente, apenas as mais jovens e solteiras.

Com os relatos dos(as) jovens entrevistados(as), percebemos que praticantes de capoeira na cidade de Amambai/MS em sua maioria são homens. Fatores como falta de incentivo para as mulheres e o modelo de masculinidade hegemônica presente nos jogos revelam questões emergentes de gênero. Segundo uma entrevistada, ao ser questionada sobre quantas rodas de capoeira contam com participação feminina em Amambai, ela revela: "Tinha só duas. E bastante homem. [...] A capoeira preserva mais o lado do homem". ${ }^{5}$ A inclusão de mais meninas e mulheres também perpassa a condição de que homens e meninos usem as convenções de masculinidade sem serem dominados por elas.

Nas falas, também se enalteceu a questão da musicalidade e corporalidade bem como a disciplina advinda com os jogos. Houve uma ênfase na importância dos jogos de capoeira nas aulas de Educação Física no ensino básico devido à sua importância histórica. A obrigatoriedade do ensino de História da África e Cultura Afro-brasileira e africana na educação básica tem estimulado práticas 
culturais como a capoeira e esta se constitui como guardiã de saberes e de proteção material de nossa cultura plural.

Na cidade de Amambai/MS, a implantação recente da capoeira em escolas públicas através de projetos do grupo Ginga Capoeira contribuiu para o conhecimento de uma nova prática. Além disso, muitos capoeiristas nas entrevistas revelaram afeição pela atividade. Atualmente, a continuidade desta prática na cidade depende de projetos, de instituições e do interesse da comunidade pela capoeira.

\section{Considerações finais}

Na pesquisa, intentamos novos olhares em relação à história local e fomos tecendo relações com o ensino da História da África, da Cultura Afro-brasileira e Africana na educação básica e os jogos de capoeira em uma perspectiva de gênero.

Dada a Lei $n^{\circ} 10.639 / 2003$, paulatinamente a capoeira é inserida em várias escolas, academias, projetos culturais, bem como nas comunidades é e compreendida como um elemento histórico e cultural de resistência. A sua prática nas escolas em Amambaí e em outros espaços sociais da cidade agrega uma significativa função educativa, inclusiva e socializadora além de compor um caleidoscópio de nossa pluralidade cultural. Assim sendo, a capoeira não é apenas uma expressão corporal e musical brasileira, mas representa um imbricado cultural, uma vez que, por meio de seus gestos particulares, transmite a quem participa a possibilidade de entender aspectos de nossa história. Além disso, acredita-se que tais práticas implicam quebras graduais de preconceitos raciais arraigados na sociedade brasileira e presentes em escolas e comunidades.

Em Amambaí, foi possível perceber que a prática da capoeira é aceita positivamente - embora outras lutas como MMA, Muay Thai, Jiu Jitsu e Boxe sejam concorrentes, sobretudo nas academias. Nas entrevistas, as praticantes femininas entornaram que os preconceitos de gênero são recorrentes e que há poucas mulheres nas rodas de capoeira. Essas questões possivelmente são advindas do processo de diferenciação negativa auferida historicamente no Brasil em relação à capoeira.

Nesse sentido, a capoeira nas escolas pode ser ensinada com diversos enfoques históricos, sobretudo na perspectiva de raça e de gênero, para que os alunos possam se identificar com as inúmeras heranças culturais, o que acaba possibilitando seu maior envolvimento na capoeira. Pudemos observar essa herança na questão da cooperação, na fala de um entrevistado: "[...] A capoeira é uma coisa que vem de todo mundo, todo mundo pode praticar. [...] Tipo, você tem que respeitar o outro. Você não pode aparecer mais que o outro, o outro também não. Tudo igualmente. E não pode querer falar "ah, eu luto mais que o outro" não pode. Tem que ser igualmente."' Isso demonstra que há um considerável apoio à igualdade de gênero e que muitos homens estão dispostos a abrir as portas de acesso às práticas da capoeira.

Nesse sentido, é lançado, para nós, o zelo pelo papel de não alimentarmos o preconceito que favorece a redução e até mesmo a negação da importância da presença africana no Brasil, com rodas de capoeira e a inserção feminina, dando, assim, a possibilidade da prática igualitária desta atividade cultural, e também propiciando com a sociedade, a criação de canais de comunicação para difundir a capoeira como esporte para ambos os gêneros. A presença feminina na capoeira pode tornar-se um locus de resistência, no sentido de uma re-significação do feminino que coloca as mulheres na posição de sujeito, e assim elas mesmas definem outras formas de "ser mulher" (ADELMAN, 2003). Com certeza, a participação feminina em diferentes práticas esportivas populares ou não traz avanços nesse sentido, e em Amambaí esse processo está ocorrendo!

\section{Notas}

1 Entre eles, destacamos: Areias (1983); Bretas (1991); Vieira (1995); Adelman (2003) e Reis, cujas obras estão elencadas na bibliografia.

2 Aqui fazemos uso dos seguintes autores também citados na bibliografia: Alberti (2004); Ferreira, e Amado (1996); Montenegro (1992); Portelli (2010) e Vilanova (1994). As entrevistas contaram com um roteiro e o uso de aparelho 
digital. As entrevistas foram transcritas em seguida, passaram pelo processo de análise e criação do texto. A cada pessoa foi solicitada assinatura de autorização para fazer uso de sua entrevista. Em relação aos cuidados na relação estabelecida com as pessoas que concedem relatos, entrevistas e depoimentos Portelli ressalta que a pessoa entrevistada não é uma "mera depositária de fatos". Por isso, o nosso trabalho residiu antes de tudo, em um "experimento de igualdade", porque é possível aprender com a pessoa que se dispõe a conceder a entrevista. Portelli destaca que pessoa que relata também tem seu juízo de valor sobre o vivenciado, e, nesse sentido, não devemos tomar uma pessoa como um informante disponível para que outro possa filosofar a partir de seu relato (2010, p. 47). Outro aspecto importante refere-se ao uso ético dos materiais coletados, orientado no princípio de que não será usado de modo a constranger a pessoa, ou transcrito de modo a ter um sentido diferente daquele que foi proferido e que se encontra gravado. É com estes cuidados que abordamos cada uma das pessoas para o trabalho que realizamos.

3 Quanto ao ideal, Foucault (1996, p. 15) observa uma passagem do primeiro discurso na obra A Genealogia da Moral, em que Nietzsche "[...] se refere a essa espécie de grande fábrica, de grande usina, em que se produz o ideal. O ideal não tem origem. Ele também foi inventado, fabricado, produzido por uma série de mecanismos, de pequenos mecanismos".

4 Entrevista concedida em março de 2015. A maioria das pessoas entrevistadas optou pelo anonimato no texto.

5 Entrevista concedida em março de 2015.

6 Entrevista concedida em abril de 2015.

\section{Referências}

ABREU, F; OLIVEIRA, J. P. de; LEAL, L. A. P. Capoeira, identidade e gênero. Salvador: EDUFBA, 2009.

ADELMAN, M. Mulheres atletas: re-significações da corporalidade feminina. Revista Estudos Feministas, Florianópolis, v. 11, n. 2, p. 445-466, jul./dez. 2003.

ALBERTI, V. Ouvir Contar: textos em história oral. Rio de Janeiro: Editora FGV, 2004.

AREIAS, A. das. O Que é capoeira. Ed. Brasiliense: São Paulo, 1983.

BRETAS, M. L. A queda do Império da navalha e da rasteira. Revista de Estudos Afro-Asiáticos, Rio de Janeiro, n. 20, p. 21-35, 1991.
BUTLER, J. Problemas de Gênero: feminismo e subversão da identidade. Rio de Janeiro: Civilização Brasileira, 2003.

CANGUILHEM, G. O normal e o patológico. 6 . ed. Tradução de Maria Tereza Redig de Carvalho Barrocas. Rio de Janeiro: Forense Universitária, 2006.

CONNEL, R. Políticas da masculinidade. Educação e Realidade, v. 20, n. 2, p. 185-206, jul./dez. 1995.

Gênero em Termos Reais. São Paulo: inVersos, 2016.

FERREIRA, M. de M.; AMADO, J. Usos \& abusos da história oral. Rio de Janeiro: FGV Editora, 1996.

FOUCAUlT, M. Microfísica do Poder. Petrópolis; Rio de Janeiro: Vozes, 1982.

A verdade e as formas jurídicas. Tradução de Roberto C. de Melo Machado e Eduardo J. Morais. Rio de Janeiro: Nau Editora, 1996.

GROSSI, M. Masculinidades: uma revisão teórica. Antropologia em Primeira Mão, Florianópolis, v. 75, p. 1-37, 2004.

MATTOS, R. A. de. História e cultura afrobrasileira. São Paulo: Contexto, 2007.

MONTENEGRO, A. T. História oral e memória: a cultura popular revisitada. São Paulo: Editora Contexto, 1992.

MUNANGA, K.; GOMES, N. L. O negro no Brasil de hoje. São Paulo: Global/Ação Educativa, 2006.

OLIVEIRA, P. P. de. "Discursos sobre a masculinidade". Revista Estudos Feministas, v. 6, n. 1, p. 91-112, 1998.

PORTELLI, A. Ensaios de História oral. São Paulo: Letra e Voz, 2010.

REIS, L.V. S. O mundo de pernas para o ar: a capoeira no Brasil. São Paulo: Publisher, 1997.

SANTOS, G. A. dos. A invenção do "ser negro": um percurso das idéias que naturalizaram a 
inferioridade dos negros. São Paulo: Educ/Fapesp; Rio de Janeiro: Pallas, 2002.

SCOTT, J. Gênero: uma categoria útil de análise histórica. Educação e Realidade, Porto Alegre, n. 16, p. 7-14, jul./dez. 1990.

VIEIRA, L. R. O Jogo de Capoeira: Cultura Popular no Brasil. Rio de Janeiro: Ed. Sprint, 1995.
VILANOVA. M. Pensar a subjetividade - estatísticas e fontes orais. In: MORAIS, M. (Org.). História Oral. Rio de Janeiro: Diadorim, 1994.

WELZER-LANG, D. A construção do Masculino: dominação das mulheres e homofobia. Revista Estudos Feministas, Florianópolis, v. 9, n. 2, p. 460-482, 2001. 